\title{
A Quantitative Investigation of Language Policy in International Schools in East Asia
}

\author{
Clayton W. Lehman ${ }^{* 1} \&$ Brett Welch ${ }^{2}$
}

* Corresponding author

E-mail: clwale@yahoo.com

1. Independent Researcher, USA.

2. Lamar University College of Education and Human Development, Center for Doctoral Studies in Educational Leadership, Beaumont, TX, USA.

\section{Article Info}

Received: February 7, 2020

Revised: July 26, 2020

Accepted: August 7, 2020

\subsection{3/repam.2020.1}

\section{How to cite}

Lehman, C. W., \& Welch, B. (2020). A quantitative investigation of language policy in international schools in East Asia. Research in Educational Policy and Management, 2(2), 1-18. https://doi.org/10.46303/repam.2020.1

\section{Copyright license}

This is an Open Access article distributed under the terms of the Creative Commons Attribution 4.0 International license (CC BY 4.0).

\begin{abstract}
Many international schools develop a formal written language policy to address language learning and use. Additionally, schools often develop a language policy as part of an authorization and or accreditation process. Although a school may have a formal written language policy, sometimes teachers are unaware the policy exists. The purpose of this study was to examine teacher knowledge of language policy in English-medium international schools in East Asia. Additionally, the researchers explored whether there were differences in teacher knowledge of language policy between schools that have an affiliation with CIS, IB, and ACS WASC and schools with no affiliation. Further, the researchers examined how often teachers followed the language policy and if the policy defined the roles of teachers. This quantitative survey-based study had 544 participants, of whom 387 were teachers. The main finding revealed that a sizeable percentage of teachers reported that their school does not have a formal written language policy or were unsure if one exists. Additional findings revealed similarities in language policy knowledge between CIS and IB schools and schools with no affiliation. Further, less than half of the teachers follow the language policy consistently, and many policies do not specify teacher roles.

\section{KEYWORDS}

Language policy; school accreditation; international schools.
\end{abstract}




\section{INTRODUCTION}

As of December 2019, ISC Research (2019) reported there were more than 11,000 international schools worldwide and earlier predicted that the number of international schools will rise to 16,000 by the year 2026 with an enrollment of 8.75 million students (Independent Education Today, 2016). While international schools traditionally served children of expatriates, a change in the demographics of international schools has occurred, and more than $80 \%$ of the student enrollment of international schools worldwide consists of local students (Lewandowski, 2012; ICEF Monitor, 2013; ISC Research, 2019). Because English has become a global language, local parents often seek to enroll their children in English-medium international schools as a means of preparing their children to study at a university in a native-speaking English country (Sears, 2015).

\section{Background}

With the rapid expansion in the international school market, some schools find themselves facing formidable competition for enrollment. As a result, establishing institutional legitimacy is a priority of many international schools (Bunnell, Fertig, \& James, 2016; 2017), with some schools seeking accreditation as a means of remaining competitive and differentiating themselves in such a competitive market (Machin, 2017). Additionally, parents view school accreditation or affiliation with organizations such as the Council of International Schools (CIS), International Baccalaureate (IB), and the Accrediting Commission for Schools, Western Association of Schools and Colleges (ACS WASC) as ensuring that a school is of high quality (ISC Research, 2018).

The decision for a school to seek authorization or accreditation can be a lengthy and arduous task. As part of the processes for obtaining authorization or accreditation status, schools gather evidence in the form of artifacts and evidence. Artifacts and evidence often include policy documents, including a formal written language policy. For example, formally written language policy development and implementation is a requirement for schools employing one or more of the International Baccalaureate programs (Wiley \& García, 2016). While a school may have a language policy on record, various stakeholders of the community may be unaware of the policy (Lehman, 2017; Lehman, 2020). Therefore, the problem is that some schools are submitting language policies as evidence for accreditation and authorization but are failing to implement the policy.

\section{Purpose and Research Questions}

The purpose of this study was to examine teacher knowledge of language policy in Englishmedium international schools in East Asia. Additionally, the researchers sought to explore whether there were differences in teacher knowledge of language policy between schools that 
have an affiliation with CIS, IB, and ACS WASC and schools with no affiliation. Further, the researchers sought to examine how often teachers followed the language policy and if the policy defined the roles of teachers.

The researchers developed four research questions to examine the current state of language policy in English-medium international schools in East Asia. The first question explored teacher knowledge of the language policy in their school. The second question sought to understand whether there were differences in teacher knowledge of language policy between schools that have an affiliation with CIS, IB, and ACS WASC and schools that have no affiliation. The third question examined the level of teacher adherence to language policy in schools that have a formal written language policy. The fourth question explored how often a formal written language policy defined the roles of the classroom teacher and ESL/EAL/ELD/TESOL teachers.

1) What is the current state of teacher knowledge of language policy in English-medium international schools in East Asia?

2) What are the differences in teacher knowledge of school language policy between English-medium international schools in East Asia that have an affiliation with CIS, IB, or ACS WASC and schools that have no affiliation? (Some schools have more than one affiliation)

3) If a school has a formal written language policy, how often are the teachers following the language policy?

4) If a school has a formal written language policy, are the roles of the classroom teachers and ESL/EAL/ELD/TESOL teachers defined in the policy?

\section{Language Policy}

With an increasing enrollment of students whose native languages are not English, a school may perceive a need for a transparent formal written language policy. A formal school language policy should state the what, how, and why of instruction (Ricento \& Hornberger, 1996). Baldauf (1993) asserted that "language policy represents the decision-making process, formally stated or implicit, used to decide which languages will be taught to (or learned by) whom for what purposes" (Baldauf, 1993, p. 83). Unfortunately, a single ready-made language policy for all schools to use does not exist (Fee, Liu, Duggan, Arias, \& Wiley, 2014). Although a school may or may not have a formal written language policy, "unwritten policy exists in the tacit practices of its teachers and administrators, and it can be inferred from their interactions with students" (Corson, 1999, p. 3). Regardless of whether a formal written language policy exists in a school, teachers will choose to follow, create, or recreate policy in their classrooms, sometimes at the detriment of the students (Menken, 2008; Shohamy, 2006; Throop, 2007).

Traditionally, administrators created a policy with the expectation that teachers and students would adhere to the requirements of the policy (Gacheche, 2010) and without studying, monitoring, and evaluating the policy to ensure that the students and school benefit 
from the policy (Fee et al., 2014; Rubin, 1971; Strunc, 2020). Often administrators will create a policy and consider the announcement of the policy as being the end of the policy planning process (Darling-Hammond, 1990), failing to understand the need for implementation (Anderson, 2003; Kennedy, 1982). As such, the policy becomes nothing more than a policy statement or a paper policy. Although the policy may be implemented, the implementation of a policy does not guarantee understanding and compliance (Darling-Hammond, 1990; Duggan, 2017; García \& Menken, 2010; Shohamy, 2006). Additionally, school language policies are sometimes ambiguous and may lack specific details that can lead to stakeholder understanding (Lehman, 2017; McClelland, 2001) or require teacher interpretation of the policy (Duggan, 2017; Timberlake, 2020; Varghese \& Stritikus, 2005). Lastly, because power imbalances exist within many schools (Carder, 2013), language policies that specify roles can avoid confusion and alleviate power imbalances often experienced by ESL/EAL/ELD/TESOL specialist teachers.

\section{Accreditation, Authorization, and Affiliation}

The Council of International Schools (CIS) is a membership community that provides accreditation for member schools. According to the membership standards for the Council of International Schools, CIS (2019a) states that "the school has documented effective written policies to safeguard and promote the welfare of all enrolled students" (sect. 5). Also, CIS awards accreditation status to a school that has "achieved high standards of professional performance in international education and has a commitment to continuous improvement" (CIS, 2019b, sect. 2). According to the Governance and Management Section of a CIS Accreditation Visiting Team Report, section C.6 states that "The governing body shall have clearly formulated policies set out in a policy manual to give consistency and order to its operations, and it shall ensure that these policies are understood by the school community." Further, CIS states that accreditation status is awarded when a school has "thought deeply about the services it offers to students, family, and community" and when a school shows that it "focuses on the quality of teaching, student learning, as well as student safeguarding and wellbeing" (CIS, 2019b, sect. 2). CIS boasts of having "a peer-based model that brings together international educators from across the world of CIS-accredited schools" (CIS, 2019b, sect 1). To serve as an accreditation team member and audit a school applying for CIS accreditation, a person must have an "affiliation with a CIS Member or CIS accredited school" (CIS, 2019c, sect. 2).

The International Baccalaureate (IB) is an international educational foundation that offers four educational programmes. These programmes are the PYP, MYP, DP, and CP. According to IB $(2011 ; 2014)$, any school using the PYP, MYP, or DP programmes is required to have a language policy. IB asserts that each school using one of the programmes "has developed and implements a language policy that is consistent with IB expectations" (IB, 2014, p. 8). This assertion is stated three more times in the same publication and in another IB publication that 
provides guidelines for developing a school language policy (IB, 2011). Although IB does not offer accreditation, schools must receive authorization from IB before offering one or more of the IB programmes.

The Western Association of Schools and Colleges (WASC) is an association that offers accreditation to schools in the western part of the United States. Through the Accrediting Commission for Schools, Western Association of Schools and Colleges (ACS WASC), ACS WASC offers accreditation services to schools below the college and university levels worldwide, including international schools in Asia. According to ACS WASC (2018), there are two primary goals for accreditation, and these goals are "certification to the stakeholders and public that the school is a trustworthy institution of learning [and] the improvement of the school's programs and operations to support student learning" (p. 1). As one of the conditions of eligibility for accreditation, ACS WASC (2018) states

The school has qualified instructional staff for all the subject and program/grade levels. The majority of teachers are fluent in English and potentially other languages. In addition the qualified staff members have had training and experience in the facilitation of English language acquisition in the areas of reading, writing, listening and speaking. (p. 6)

In the self-study report for accreditation in Thailand in accordance with the requirements of the Office for National Education Standards and Quality Assessment (ONESQA), ACS WASC states "necessary evidence will be observed and may be collected; for instance, assessment data, assessment rubrics, report progress, achievement test results, interviews, homework and work assignments, language policy and assessment policy, etc." (ACS WASC, 2016, p. 59).

\section{METHODOLOGY}

\section{Participants}

A random sampling was utilized as school websites were searched and mined for names and contact information for potential participants. Participants of this study were targeted because they were teachers and administrators in English-medium international schools in East Asian countries. The researchers sent a single email with an introduction and a web link to a survey hosted by Survey Monkey to 5473 potential participants in more than 500 schools. There was a total of $544(\mathrm{~N}=544)$ participants, of whom 157 were administrators and 387 teachers. Although there were participants from 15 countries and city-states, the researchers had initially targeted seventeen; however, the researchers did not receive any responses from potential participants in the two countries of Myanmar and Nepal. The researchers primarily used the websites for Search Associates, International School Review, and East Asia Regional Council of School (EARCOS) to define geographical limits and to develop a list of international schools to target. Search Associates is an international school recruitment organization; International School Review is a website that provides a platform for stakeholders to post reviews of international schools, English-medium schools, and international programs; EARCOS is an 
organization of international schools in East Asia. Additional resources for locating names of international schools included Internet searches, LinkedIn profiles, and other entities that provide information and services for expatriates in foreign countries. Table 1 provides geographical locations and data for both administrators and teachers.

Table 1. Participant Demographics

\begin{tabular}{|c|c|c|c|c|}
\hline $\begin{array}{l}\text { Country or } \\
\text { City-state }\end{array}$ & $\begin{array}{l}\text { Participants with } \\
\text { a formal written } \\
\text { language policy }\end{array}$ & $\begin{array}{l}\text { Participants without } \\
\text { a formal written } \\
\text { language policy }\end{array}$ & $\begin{array}{l}\text { Participants with no } \\
\text { knowledge of a formal } \\
\text { written language policy* }\end{array}$ & Total \\
\hline Cambodia & 3 & 2 & 2 & 7 \\
\hline China & 115 & 26 & 28 & 169 \\
\hline East Timor & 2 & 0 & 0 & 2 \\
\hline Hong Kong & 17 & 1 & 3 & 21 \\
\hline Indonesia & 20 & 4 & 2 & 26 \\
\hline Japan & 26 & 5 & 2 & 33 \\
\hline Laos & 1 & 0 & 0 & 1 \\
\hline Malaysia & 21 & 4 & 9 & 34 \\
\hline Mongolia & 6 & 2 & 3 & 11 \\
\hline Philippines & 15 & 0 & 5 & 20 \\
\hline Singapore & 16 & 1 & 3 & 20 \\
\hline South Korea & 37 & 3 & 7 & 47 \\
\hline Taiwan & 22 & 3 & 9 & 34 \\
\hline Thailand & 38 & 15 & 11 & 64 \\
\hline Vietnam & 29 & 13 & 13 & 55 \\
\hline Total & 368 & 79 & 97 & 544 \\
\hline
\end{tabular}

\section{Design}

The researchers used an observational quantitative research design that employed a crosssectional survey to gather data (Creswell, 2012). With a cross-sectional survey design, the researchers do not manipulate a variable but instead seek to capture data at a single point in time. According to Hornberger (2015), a survey is one way to study language policy, and because this study involved participants from fifteen countries and city-states in East Asia, an electronic survey was used to gather data.

\section{Instrument}

The current study reports unreported data acquired during a more extensive study for a doctoral dissertation. For the original study, the researchers used the Teaching and Learning International Survey (TALIS) questionnaire developed by the Organization for Economic Cooperation and Development (OECD) as a guide for the survey. According to He and Kubacka (2015), the TALIS questionnaire passed rigorous validation protocols in its development. 
Additionally, experts in the field were used to establish content validity (Creswell, 2012; Salkind, 2013).

As part of the original study, the researchers used two different surveys, one for administrators and one for teachers. All questions were nominal or ordinal (see Table 2. Also, see Appendix). The Likert type question contained five points, not including two points, which served as disqualifiers. None of the questions in the survey were mandatory. Lastly, the original study received IRB approval through the university in which the primary researcher was pursuing a doctoral degree in educational leadership.

Table 2. Survey Questions and Research Questions

\begin{tabular}{lcc}
\hline \multicolumn{1}{c}{ Question } & Administrators & Teachers \\
\hline \#1 Nominal & $\begin{array}{c}\text { Language policy } \\
\text { (Yes or No) }\end{array}$ & Language policy \\
\#2 Nominal & Accreditation information & (Yes, No, or I do not know) \\
\#3 Likert & Accreditation information \\
\#4 Nominal & $\begin{array}{c}\text { Teacher roles defined in the } \\
\text { policy }\end{array}$ & $\begin{array}{c}\text { Follow the policy } \\
\text { Teacher roles defined in the } \\
\text { policy }\end{array}$ \\
\hline
\end{tabular}

\section{Data Analysis}

The researchers used SPSS software (v. 25) to perform Pearson chi-square tests $\left(\chi^{2}\right)$ with an alpha level of .05. The Pearson chi-square test is a nonparametric test used to measure the distribution of frequencies (Salkind, 2013). Additionally, the Pearson chi-square test can evaluate nominal data (Creswell, 2012). All data analyzed with Pearson chi-square tests met the assumptions as specified by McHugh (2013).

\section{RESULTS}

In the first survey question, of the 157 administrator participants, 129 (82.2\%) answered that there was a formal written language policy in their school, while 28 (17.8\%) administrator participants revealed that there was not a formal written language policy in their school. Also, in the first question of the survey and for the first research question, of the 387 teacher participants, $61.5 \%$ reported there was a formal written language policy in their school. Fiftytwo of the teacher responses representing $13.4 \%$ revealed there was no formal written language policy. Lastly, $25.1 \%$ of the teacher participants chose to answer they did not know if there was a formal written language policy in their school (see Table 3). In the first question of the survey, administrators were only given the options of yes or no, while teachers were provided with an extra option of answering that they did not know. 
Table 3. Teacher Knowledge of Language Policy $(n=387)$

\begin{tabular}{lcc}
\hline Knowledge of Policy & Teacher Participants & Percent \\
\hline Yes & 238 & $61.5 \%$ \\
No & 52 & $13.4 \%$ \\
I do not know & 97 & $25.1 \%$ \\
Total & 387 & $100 \%$ \\
\hline
\end{tabular}

The second research question sought to investigate differences in teacher knowledge of language policy between English-medium international schools in East Asia that have an affiliation with IB, CIS, or ACS WASC and schools that have no affiliation. Table 4 provides a breakdown of the teachers' answers for the second survey question concerning school affiliation with CIS, IB, ACS WASC, or no affiliation combined with their knowledge of the language policy in their school.

Table 4. Teacher Knowledge of Language Policy by Affiliation*

\begin{tabular}{lcccc}
\hline Affiliation & Yes & No & Do Not Know & Total \\
\hline CIS & $87=61.7 \%$ & $17=12.1 \%$ & $37=26.2 \%$ & 141 \\
IB & $122=65.6 \%$ & $20=10.8 \%$ & $44=23.7 \%$ & 186 \\
ACS WASC & $112=70.0 \%$ & $19=11.9 \%$ & $29=18.1 \%$ & 160 \\
No affiliation & $31=46.3 \%$ & $16=23.9 \%$ & $20=29.9 \%$ & 67 \\
\hline
\end{tabular}

* Some teachers were in schools that have more than one affiliation.

The results of a Pearson chi-square test revealed that there was no statistically significant difference in teacher knowledge of the language policy between schools that have no affiliation with CIS (Group 1: $n=246$ ) and schools affiliated with CIS (Group 2: $n=141), X^{2}(2, N=387)=$ $0.438, p=0.803$ (see Figure 1).

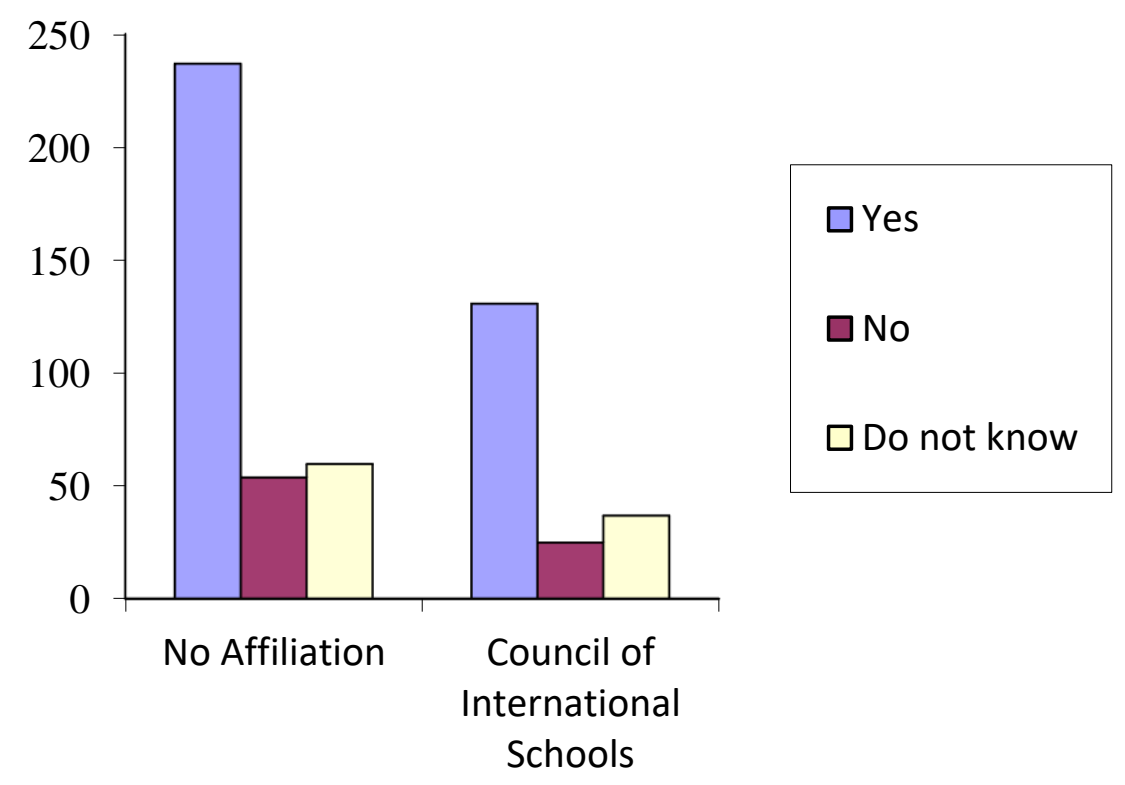

Figure 1. Teacher knowledge of language policy in CIS schools vs. non-CIS schools 
The results of a Pearson chi-square test revealed that there was no statistically significant difference in teacher knowledge of the language policy between schools that have no affiliation with IB (Group 1: $n=201$ ) and schools affiliated with IB (Group 2: $n=186), X^{2}(2, \mathrm{~N}=387$ ) = 3.179, $p=0.204$ (see Figure 2).

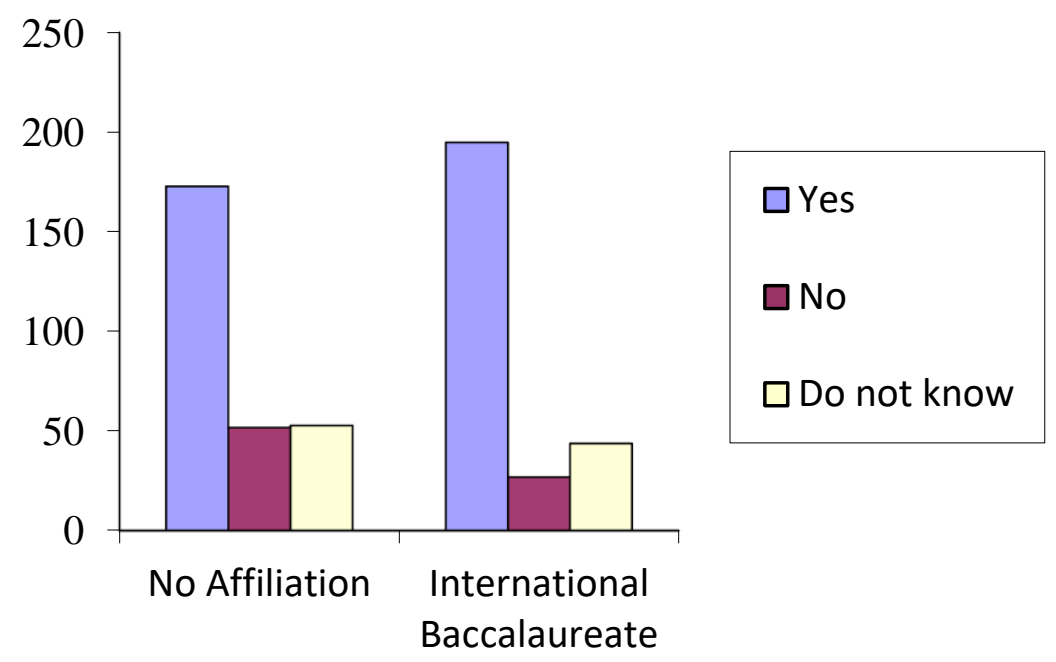

Figure 2. Teacher knowledge of language policy in IB schools vs. non-IB schools

The results of a Pearson chi-square test revealed that there was a statistically significant difference in teacher knowledge of the language policy between schools that have no affiliation with ACS WASC (Group 1: $n=227$ ) and schools affiliated with ACS WASC (Group 2: $n=160$ ), $X^{2}$ $(2, N=387)=8.942, p=0.011$ (see Figure 3).

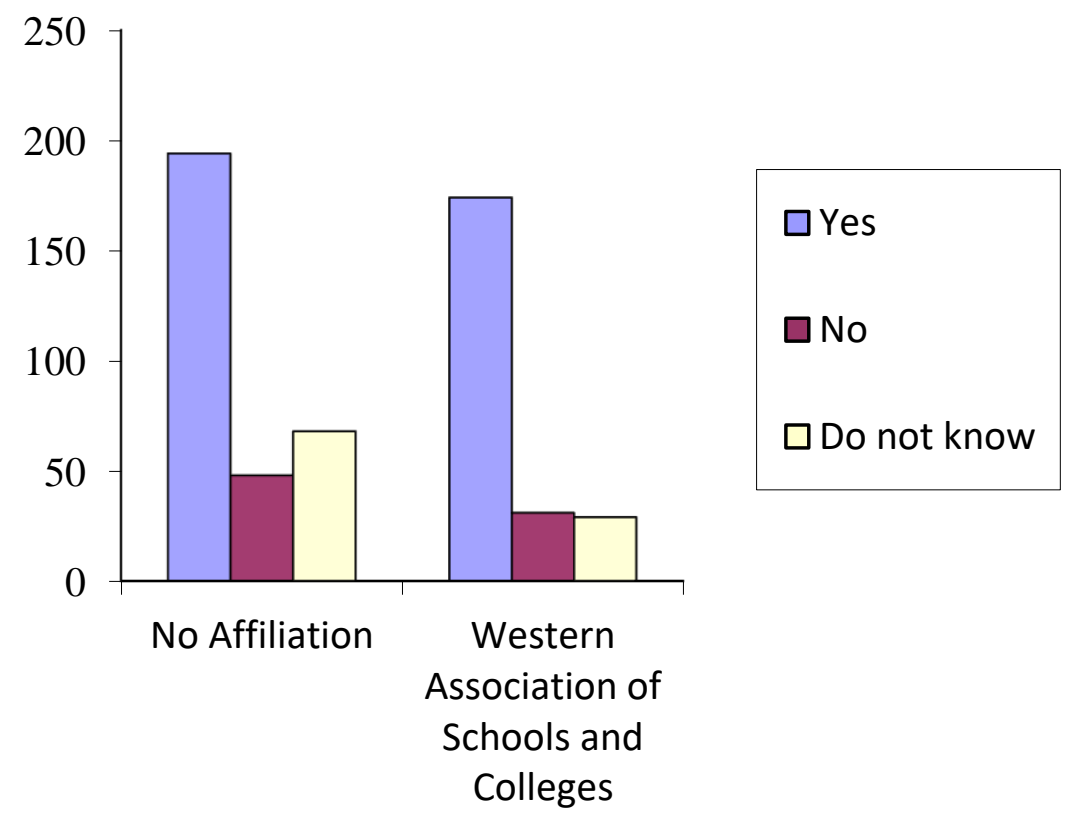

Figure 3. Teacher knowledge of language policy in WASC schools vs. non-WASC schools 
A fourth Pearson chi-square test measured the difference between schools that had no affiliation with CIS, IB, or ACS WASC and schools that were affiliated with CIS, IB, or ACS WASC. The results of a Pearson chi-square test revealed that there was a statistically significant difference in teacher knowledge of the language policy between schools that have an affiliation with CIS, IB, or ACS WASC (Group 1: $n=320$ ) and schools without an affiliation with CIS, IB, or ACS WASC (Group 2: $n=67), X^{2}(2, N=387)=10.374, p=0.006$ (see Figure 4).

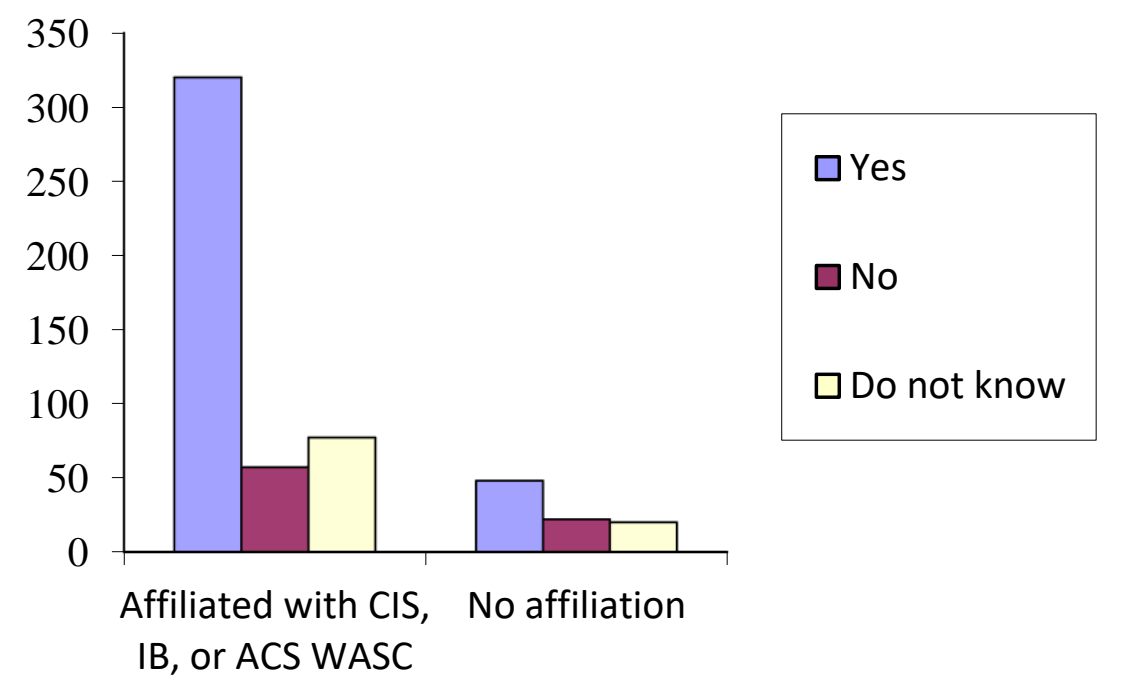

Figure 4. Teacher knowledge of language policy in affiliated schools vs. non-affiliated schools

The third question sought to investigate how often teachers follow the school language policy. Of the 238 teacher participants who responded by answering their school had a formal written language policy, 232 provided an answer to what degree they followed the language policy. Ninety-eight or $42.2 \%$ of the 232 respondents revealed they followed the policy consistently, and $36.6 \%$ responded that they followed the policy most of the time. Thirty-nine teachers chose to answer that they followed the policy to some extent while five teachers revealed they followed the policy very little, and an equal number revealed they do not follow the policy at all (see Table 5).

Table 5. Teachers Following Language Policy ( $n=232)$

\begin{tabular}{lcc}
\hline Degree of adherence & Number of teachers & Percentage \\
\hline Do not follow the policy & 5 & $2.2 \%$ \\
Very little & 5 & $2.2 \%$ \\
Some extent & 39 & $16.8 \%$ \\
Most of the time & 85 & $36.6 \%$ \\
Consistently & 98 & $42.2 \%$ \\
Total & 232 & $100 \%$ \\
\hline
\end{tabular}


The final research question sought to investigate how often the school language policy defines the roles of the classroom teachers and the ESL/EAL/ELD/TESOL teachers. Of the 544 participants, including administrators and teachers, 365 participants revealed that their school had a formal written language policy. Of those 365 participants, 363 chose to respond to the question asking if the roles of the classroom teachers and ESL/EAL/ELD/TESOL teachers were defined within the language policy. Of the 363 who chose to respond, 196 answered that the roles were defined. Answering that the roles were not defined were 116, and 51 responded that they did not know if the roles were specified (see Table 6).

Table 6. Roles Defined in Language Policy ( $n=363$ )

\begin{tabular}{lcccc}
\hline Administrators \& Teachers & Yes & No & Do Not Know & Total \\
\hline All respondents & 196 & 116 & 51 & 363 \\
Percentage & $54 \%$ & $32 \%$ & $14 \%$ & $100 \%$ \\
\hline
\end{tabular}

\section{DISCUSSION}

The data revealed in Table 3 shows 38.5\% percent of teachers in international schools in East Asia are either aware that their school does not have a formal written language policy or are unaware of whether such a policy exists in their school. While it has been reported that more than $80 \%$ of the student enrollment of international schools worldwide consists of local students (ICEF Monitor, 2013; ISC Research, 2019; Lewandowski, 2012), the percentage of non-native English-speaking enrollment in many international schools in East Asia is often much higher, sometimes being $100 \%$. As such, a formal written language policy can provide a school with a clear plan for the use of language(s) within the school community.

As the international school market expands and schools compete against one another for enrollment, many schools strive to establish institutional legitimacy by acquiring accreditation(s) and or authorization(s) from various organizations and entities. As part of the processes for obtaining authorization or accreditation status, schools often develop a formal written language policy. According to Bunnell et al. (2016), international schools place a high priority on establishing institutional legitimacy. Moreover, Machin (2017) discussed how international schools are always striving to differentiate themselves to stay competitive, and accreditation is one method schools may seek to distinguish themselves from others in the marketplace. While Macdonald (2007) asserted that one could argue that IB was a dominant factor of differentiation in the international school market, it can now be seen as being an enabler. Although schools may be striving to differentiate themselves, the question arises as to whether such actions by some schools are merely superficial.

Analysis of the data further revealed that many teachers are working in international schools affiliated with CIS, IB, or ACS WASC that do not have a formal written language policy or have not provided teachers with enough information, training, or support to know if a policy 
does exist. When the numbers are combined, a sizeable percentage of participants is revealed (see Table 7).

Table 7. Teacher Knowledge of Language Policy by Affiliation* with No and Do Not Know Combined

\begin{tabular}{lccc}
\hline Affiliation & Yes & $\begin{array}{c}\text { No and Do Not } \\
\text { Know Combined }\end{array}$ & Total \\
\hline CIS & $87=61.7 \%$ & $54=38.3 \%$ & 141 \\
IB & $122=65.6 \%$ & $64=34.4 \%$ & 186 \\
ACS WASC & $112=70.0 \%$ & $48=30.0 \%$ & 160 \\
No affiliation & $31=46.3 \%$ & $36=53.7 \%$ & 67 \\
\hline
\end{tabular}

*Some participants were in schools with more than one affiliation

While IB specifically calls for authorized schools to have a written language policy, CIS and ACS WASC, to the researchers' knowledge, do not. However, section C. 6 of the CIS Accreditation Visiting Team Report asserts there should be a policy manual containing policies that are understood by the school community. Additionally, CIS states that accreditation is awarded when a school has "thought deeply about the services it offers to students, family, and community" (CIS, 2019b, sect. 2). In the self-study report for ACS WASC accreditation in Thailand, language policy is listed as an example of necessary evidence. Considering $38.3 \%$ of the teacher participants in CIS schools, $34.4 \%$ of the teacher participants in IB schools, and $30.0 \%$ of the teacher participants in ACS WASC schools revealed there was either no policy or lacked knowledge of a policy points to the possibility that some language policies are nothing more than policy statements or paper policies.

Overall, the lack of language policy or knowledge of policy in non-affiliated schools was above fifty percent. However, the percentages of teachers in schools affiliated with $\mathrm{CIS}$, IB, and ACS WASC answering there was no policy or did not know if a policy existed is disturbing. Teachers revealing that there is not a policy or not knowing if a policy exists in CIS, IB, or ACS WASC affiliated schools suggests the possibility of poor policy implementation by school administrators or outright negligence. These situations are extremely concerning, especially when parents view authorization and accreditation as indicators of schools being good (ISC Research, 2018), thus warranting the payment of high tuition fees. Moreover, the data further indicates there is the potential for oversight during the accreditation and authorization proceedings of CIS, IB, and ACS WASC.

Of additional concern is the number of teachers who are not consistently following the formal written language policy in the schools that have a policy. Only $42.2 \%$ of teacher participants in schools with a formal written language policy responded that they consistently followed the policy, which means the remaining $57.8 \%$ are not consistently following the formal written language policy in their school to one degree or another (see Table 5). Understanding 
why teachers are following the language policy or why not is an important task each school should engage in during the policy cycle (Anderson, 2003).

Classroom teachers, especially those new to international schools, may succumb to feelings of being overwhelmed due to their lack of training in working with English language learners (Walker, Shafter, \& liams, 2004) or lack of organizational support (Varghese \& Stritikus, 2005). Some teachers in schools with a formal written language policy may not follow the policy consistently because they disagree with the language policy or make decisions based on their understandings (Duggan, 2017; Throop, 2007; Varghese \& Stritikus, 2005). Although schools that have a formal written language policy tend to provide a higher frequency of languagespecific professional development for school staff, this development may not be in a form needed to sustain language policy implementation (Lehman, 2019). Considering the high numbers of local students that are attending international schools (ICEF Monitor, 2013; ISC Research, 2019; Lewandowski, 2012), teachers should receive training concerning language policy and the implementation of the language policy.

According to Ricento and Hornberger (1996), a formal written language policy should state the what, how, and why of instruction. Additionally, a formal written language policy should specify when, how often, and what kind of language-specific professional development will occur to support the implementation of the language policy. According to Table 6, 54\% of participants in schools with a formal written language policy answered that the policy specified the roles of the classroom teachers and the ESL/EAL/ELD/TESOL teachers. On the contrary, $46 \%$ of the participants in schools with a formal written language policy either said no or did not know if the roles of the classroom teachers and the ESL/EAL/ELD/TESOL teachers were specified (see Table 6). Stating the how in a school language policy involves defining the roles of the classroom teachers and the ESL/EAL/ELD/TESOL specialist teachers working with English language learners, especially in schools that use a second language acquisition (SLA) instructional model incorporating push-in support. Specifying the roles may avoid confusion and power imbalances that can affect both teachers and students (Carder, 2013; Lehman, 2017).

\section{CONCLUSION}

The main finding of the study revealed that 38.5\% percent of teachers in international schools in East Asia reported that their school either does not have a formal written language policy or were unsure if one exists. Another finding of the study revealed that $38.3 \%$ of teachers in schools affiliated with CIS, 34.4\% affiliated with IB, and $30.0 \%$ affiliated with ACS WASC reported that their school either does not have a formal written language policy or were unsure if one exists. Also, the researchers found similarities in language policy knowledge between $\mathrm{CIS}$ and IB schools and schools with no affiliation. Additionally, the researchers found that only $42.2 \%$ of the teacher participants in schools with a formal written language policy followed the policy consistently. Lastly, only $54 \%$ of the participants in schools with a formal written language policy 
revealed that the language policy specified the roles of the classroom teachers and the ESL/EAL/ELD/TESOL teachers.

\section{Assumptions and Limitations}

The researchers assumed that participants answered the survey questions truthfully. The researchers further assumed that participants participated and responded to questions in the capacity of being a professional educator. This study was limited to participants for which contact information could be located on the Internet. Another limitation of this study is that participants answered questions based on their unique perspective and experience at their particular school.

\section{Recommendations}

The findings of this study should call into question the practices of school leadership and entities offering authorization or accreditation to international schools. The researchers recommend that schools with formal written language policies ensure that all stakeholders are aware of the existence and contents of the policy. Additionally, the researchers recommend that international schools with formal written language policies examine their processes for ensuring the policy is fully implemented and experiences regular evaluation. Also, the researchers recommend schools without formal written language policies establish a steering committee to develop and implement a formal written language policy for their school community. The researchers encourage further research into the authorization and accreditation processes of not only CIS, IB, and ACS WASC, but also other entities that offer similar services to international schools. Additionally, the researchers encourage further research to discover why teachers in international schools decide to follow or not to follow a formal written language policy.

\section{Closing Remarks}

This study occurred as a result of the observations made by the primary researcher while working in international schools in East Asia. In closing, the primary researcher asserts that some administrators and schools are submitting language policies as artifacts or evidence without ever implementing the policies. The primary researcher further posits that members of authorization or accreditation teams are not looking deep enough for proof of policy implementation. Lastly, the primary researcher calls into question the peer-review processes used by accrediting and authorizing entities since members of peer-review teams could consist of administrators who may not have adequately developed and or implemented school policies yet were submitted as artifacts or evidence during their school's accreditation or authorization proceedings. 


\section{REFERENCES}

ACS WASC. (2016). ACS WASC focus on learning accreditation manual: 2017 international edition. Retrieved from http://www.acswasc.org

ACS WASC. (2018). ACS WASC international initial visit procedures manual (ed. 2018).

Retrieved from http://www.acswasc.org

Anderson, J. E. (2003). Public policymaking: An introduction (5th ed.). New York, NY: Houghton Mifflin.

Baldauf, R. B. (1993). 'Unplanned' language policy and planning. Annual Review of Applied Linguistics, 14, 82-89. https://doi.org/10.1017/S0267190500002828

Bunnell, T., Fertig, M., \& James, C. (2016). What is international about international schools? An institutional legitimacy perspective. Oxford Review of Education, 42(4), 408-423.

Bunnell, T., Fertig, M., \& James, C. (2017). Establishing the legitimacy of a school's claim to be "International": The provision of an international curriculum as the institutional primary task. Educational Review, 69(3), 303-317. https://doi.org/10.1080/00131911.2016.1213224

Carder, M. (2013). Managerial impact on programmes for second language learners in international schools. Retrieved from http://mclanguage.tripod.com

CIS. (2019a). Membership standards. Retrieved from https://www.cois.org

CIS. (2019b). What does it mean to be a CIS accredited school. Retrieved from https://www.cois.org

CIS. (2019c). Evaluation teams. Retrieved from https://www.cois.org

Corson, D. (1999). Language policy in schools. A resource for teachers and administrators. Mahwah, NJ and London, England: Lawrence Erlbaum.

Creswell, J. W. (2012). Educational research: Planning, conducting, and evaluating quantitative and qualitative research ( $4^{\text {th }}$ ed.). Boston, MA: Allyn \& Bacon.

Darling-Hammond, L. (1990). Instructional policy into practice: "The power of the bottom over the top." Educational Evaluation and Policy Analysis, 12(3), 339-347. https://doi.org/10.2307/1164357

Duggan, J. (2017). Interpreting and negotiating language policy at the local level: A case study from Catalan-speaking Spain. Bellaterra Journal of Teaching \& Learning Language \& Literature, 10(2), 77-91. https://doi.org/10.5565/rev/jt13.736

Fee, M., Liu, N., Duggan, J., Arias, B., \& Wiley, T. (2014). Investigating language policies in IB world schools: Final report. International Baccalaureate Organization. Retrieved from https://www.ibo.org

Gacheche, K. (2010). Challenges in implementing a mother tongue-based language-ineducation policy: Policy and practice in Kenya. POLIS Journal, 4(Winter), 1-45.

García, O., \& Menken, K. (2010). Moving forward: Ten guiding principles for teachers. In K. Menken \& O. García (Eds.), Negotiating language education policies: Educators as policymakers (pp. 262-268). New York, NY: Routledge.

He, J., \& Kubacka, K. (2015). Data comparability in the teaching and learning International survey (TALIS) 2008 and 2013 (OECD Education Working Papers, No. 124). Paris, France: OECD. https://doi.org/10.1787/5jrp6fwtmhf2-en

Hornberger, N. (2015). Selecting appropriate research methods in LPP research: Methodological rich points. In F. M. Hult \& D. C. Johnson (Eds.), Research methods in language policy and planning: A practical guide (pp. 9-20). West Sussex, UK: Wiley Blackwell. 
ICEF Monitor. (2013). International school enrolment on pace to reach \$60 billion by 2022.

Retrieved from http://monitor.icef.com

Independent Education Today. (2016). Huge global demand for English-medium K-12 education. Retrieved from https://ie-today.co.uk

International Baccalaureate. (2011). Language and learning in IB programmes. Cardiff, UK: International Baccalaureate Organization.

International Baccalaureate. (2014). Programme standards and practices. Cardiff, UK: International Baccalaureate Organization.

ISC Research. (2018). International school market sees growth and new opportunities this year. ISC Research. Retrieved from www.iscresearch.com

ISC Research. (2019). ISC research. Retrieved from https://www.iscresearch.com.

Kennedy, C. (1982). Language planning. Language Teaching, 15(04), 264-284. https://doi.org/10.1017/S0261444800009708

Lehman, C. W. (2017). Early childhood: Language and bullying in an English-medium school in China. The Electronic Journal for English as a Second Language, 21(1),1-16. Retrieved from http://www.tesl-ej.org

Lehman, C. W. (2019). Language policy in English-medium international schools in East Asia (UMI No. 13421976). [Doctoral dissertation, Lamar University]. ProQuest Dissertations and Theses database.

Lehman, C. W. (2020). Parent knowledge and preferences of language learning and use in an international school in Vietnam. Manuscript submitted for publication.

Lewandowski, N. (2012, January 5). International education is becoming a goldmine. Retrieved from https://expatmarketing.com

Macdonald, J. (2007). Daring to be different: How differentiation strategies help determine the educational success and fiscal health of international schools. Journal of Research in International Education, 6(2), 151-169.

Machin, D. (2017). The great Asian international school gold rush: An economic analysis. Journal of Research in International Education, 16(2), 131-146. https://doi.org/10.1177/1475240917722276

McClelland, R. (2001). Managing assessment in the international school. In S. Blandford \& M. Shaw (Eds.), Managing international schools (pp. 48-62). London: Routledge Farmer.

McHugh, M. L. (2013). The chi-square test of independence. Biochemia Medica, 23(2), 143-149. https://doi.org/10.11613/BM.2013.018

Menken, K. (2008). English language learners left behind. Clevedon: Multilingual Matters.

Ricento, T. K., \& Hornberger, N. H. (1996). Unpeeling the onion: Language planning and policy and the ELT professional. TESOL Quarterly, 30(3), 401-427. https://doi.org/10.2307/3587691

Rubin, J. (1971). Evaluation and language planning. In J. Rubin \& B. H. Jernudd (Eds.), Can language be planned? (217-252). Hawaii: University Press of Hawaii.

Salkind, N. J. (2013). Statistics for people who (think they) hate statistics ( $3^{\text {rd }}$ ed.). Thousand Oaks, CA: SAGE Publications.

Sears, C. (2015). Second language students in English-medium classrooms: A guide for teachers in international schools (Vol. 2). Clevedon: Multilingual Matters.

Shohamy, E. G. (2006). Language policy: Hidden agendas and new approaches. New York, NY: Routledge.

Strunc, A. (2020). Editorial: Are they listening? Policy makers and their role in public education. 
Research in Educational Policy and Management, 2 (1), i-iii.

https://doi.org/10.46303/repam.02.01.ed

Throop, R. (2007). Teachers as language policy planners: Incorporating language policy planning into teacher education and classroom practice. Working Papers in Educational Linguistics,

22(2), 45-65. Retrieved from http://repository.upenn.edu

Timberlake, M. (2020). Recognizing ableism in educational initiatives: Reading between the lines. Research in Educational Policy and Management, 2 (1), 84-100.

https://doi.org/10.46303/repam.02.01.5

Varghese, M. M., \& Stritikus, T. (2005). "Nadie Me Dijó [Nobody Told Me]" Language policy negotiation and implications for teacher education. Journal of Teacher Education, 56(1), 73-87. https://doi.org/10.1177/0022487104272709

Walker, A., Shafer, J., \& liams, M. (2004). Not in my classroom: Teacher attitudes towards English language learners in the mainstream classroom. NABE Journal of Research and Practice, 2(1), 130-160. Retrieved from https://www2.nau.edu/nabej-p/ojs

Wiley, T. G., \& García, O. (2016). Language policy and planning in language education: Legacies, consequences, and possibilities. The Modern Language Journal, 100, 48-63.

https://doi.org/10.1111/modl.12303 


\section{APPENDIX}

\section{Survey Questions}

The following were survey questions analyzed in the present study. Administrators were not provided with the third option in question one. Also, administrators were not asked question three.

1. Does your school have a formal written language policy?
1) Yes
2) No
3) I do not know

2. Does your school maintain membership or accreditation status with any of the following organizations? (Mark all that apply)
1) Council of International Schools
2) International Baccalaureate
3) Western Association of Schools and Colleges
4) No

3. If your school has a formal written language policy, do you follow the policy?
1) There is no language policy
2) I do not know if there is a language policy
3) I do not follow the policy
4) Very little
5) To some extent
6) Most of the time
7) Consistently

4. Does the language policy specifically state the roles of the classroom teachers and the ESL/EAL/ELD/TESOL specialist teachers?
1) Yes
2) No
3) No language policy
4) I do not know 